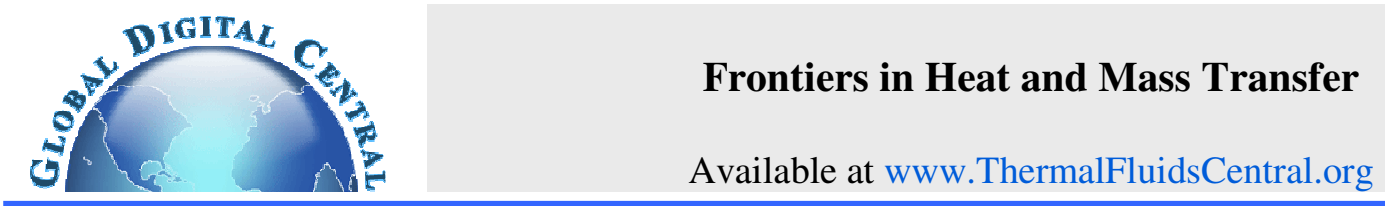

\title{
STUDY ON FLOW AND TEMPERATURE BEHAVIOR OF CATALYTIC HONEYCOMB MONOLITH COMBUSTION FURNACE OF NATURAL GAS TO PROPERTIES OF GLAZED TILES
}

\author{
Shihong Zhang*, Meixian Wei, Hui Yang \\ School of Environment and Energy Engineering, Beijing University of Civil Engineering and Arch., Beijing, 100044, China
}

\begin{abstract}
This article discussed flow and temperature characteristics of the catalytic combustion furnace based the combustion of lean natural gas-air mixtures in catalytic honeycomb monoliths. Catalytic combustion as a developing technology could make the pollutant emissions (CO and NOx) to near zero. Within the porous structure, the reactions then take place on the catalytic sites. A heterogeneous catalytic process includes more than one phase. Usually the catalyst is a solid and the reactants and products are in liquid or gaseous form. According to the applications of low- carbon catalytic combustion furnace, heating glazed tiles with pure solid texture, rich melodic style and glamorous colors were obtained. It was found pleasing to both the eye and the mind. Also the water absorption and frost resistance of glazed tiles were accorded with Chinese national standard. It is feasible to apply the glazed tiles heated by the catalytic combustion furnace to the architectural decoration of buildings.
\end{abstract}

Keywords: Low-carbon catalytic combustion furnace; flow and temperature characteristics; Frost resistance.

\section{INTRODUCTION}

Ceramic tiles are usually decorated with a glaze coating, which seal the body and provide the tiles outer surface with the aesthetic qualities, such as color, gloss and opacity, as well as the desired technical characteristics, such as hardness, chemical resistance and scratch resistance that required for its intended use (Gomez-Tena et al., 2009). In Chinese ancient traditional architectures, glaze with many kinds of colors is very popular. Many ancient Chinese palaces were built by emperors, serving only for them and their families. They are mostly made of glazed tiles, glazed bricks, and even the walls are also decorated with glazed (Cheng et al., 2008). Now the glazed tiles usually use on architectural decoration and those ancient buildings that are seriously damaged so that it requires a lot of tile pieces.

But in the energy structure of the ceramic industry furnaces, they mainly use coal as fuel. But there are many problems widely existing in current coal-fired industrial boilers and kilns in China, such as backward technology, and low efficiency, which are polluted and difficult to supervise. They emit dark smoke that is harmful to the air (Wang et al., 2013). What is more, recent epidemiologic studies have shown that exposure to environmental air pollution is associated with an increase in mortality and higher morbidity, such as asthma, chronic obstructive pulmonary disease and cancer (Cohen et al., 2005). Obviously, our consumption of fossil fuels must be reduced, partly due to limited supply and uncertainty in the future, partly due to the adverse effects on the environment. And it can rely on the new type of combustion technology to reduce the emission of global warming gas and other pollutant.

Due to the great interest in reducing emissions of combustion pollutants and improving thermal efficiency, many research projects have resulted (Pfefferle and Pfefferle, 1987). Compared with other fuels, natural gas (methane), as a kind of fuel, has been widely used in many fields because of its abundant reserves and relatively clean characteristics (Ronney, 2003). However, due to the high chemical stability of methane molecules, only a few percent of the methane concentration and large gas flow rate, it makes $\mathrm{C}-\mathrm{H}$ bond difficult to be activated (Hicks et al., 1990). Therefore, methane is not easy to completely burn. What is more, catalytic combustion are main ways to methane complete oxidation ( $\mathrm{Li}$ et al., 2016). It was first demonstrated by Pfefferle in 1970 that heterogeneously catalyzed gas-phase combustion and catalytic combustion was shown to be an efficient method for burning fuels in lean fuel-air mixtures without significant formation of pollutants. Since then, catalytic combustion attracted a great attention due to its ability of burning fuels outside the flammability limits, and as a result, at relatively low temperatures and high efficiency, thus simultaneously reducing the impact of the $\mathrm{NO}_{\mathrm{x}}$ on the environment at the same time, while the emission of $\mathrm{CO}$ and unburned fuels is very low (Lee and Trimm, 1995; Zwinkels et al., 1993). Because of the many advantages of the catalytic combustion, it has so far found limited applications.

So far, gas catalytic combustion has been applied in gas cookers and cooking plates. It has proved to be a promising technology for cleaning, power modulation and emission. The results have shown that the burner produced extremely low $\mathrm{NO}_{\mathrm{x}}$ emissions of $\mathrm{NO}_{\mathrm{x}}$, and with acceptable CO-levels $(0-15 \mathrm{mgCO} / \mathrm{kWh})$, and the thermal efficiencies is relatively high over a broad range of power inputs (40-50\% for $1-4 \mathrm{~kW})$ and a long catalyst life-time $(>10000 \mathrm{~h})$. And it is also believed that the high emissions of unburned hydrocarbons measured at slow cooking mode $(<1 \mathrm{~kW})$ can be overcome by developing and implementing an appropriate heat-exchanger with the burner (Jannasch et al., 2006). So, this is a great contribution to gas stoves. Besides, catalytic combustion also can be applied in commercial class gas engines and micro gas turbines to reduce $\mathrm{NO}_{\mathrm{x}}$ emissions and improve flame stability (Yuan et al., 2008). In the burner, these oxidation catalysts not only increase the stability of ultra-thin combustion, but also generate near-zero emission 
of pollutants, thus providing a reasonable alternative for the unstable low $\mathrm{NO}_{\mathrm{x}}$ combustion technology, such as lean burn (Dupont et al., 2000).

At present, the research of catalytic combustion technology was also mainly related to the preparation of the catalyst. Many efforts have been made to design catalysts with good activity and selectivity. The most commonly used catalysts are noble metals ( $\mathrm{Pt}, \mathrm{Pd}, \mathrm{Au}$, etc.) and metal oxides catalysts, which are much expensive. Rare earth elements (REE), as important promoters of special electronic structures, have attracted wide attention from researchers in recent years. Lately, a series of rare earth elements (REE)-modified Pt/MCM-41 catalysts were prepared. The influence of rare earth doped MCM-41 on the performance of $0.2 \%$ platinum/MCM-41 was studied. XRD and N2 adsorption indicate that MCM-41 with high specific surface area and large pore volume has a highly ordered hexagonal mesostructure. Therefore, a more efficient catalyst can be obtained by dispersing the rare earth oxides of $\mathrm{Pt}$ on the high specific surface area of MCM-41, thus providing more active sites for the reaction, thus reducing the cost (Li et al., 2017).

In the recent study, the catalytic combustion furnace was concerned and an extensive experimental investigation was carried out to study on the characteristics of natural gas catalytic combustion furnace. Take this opportunity, we hope that the catalytic combustion furnace can provide tiles of similar quality and at the same time, glazed tiles manufacturing of low pollution and low emission production may be provided. By heating glazed tiles, the flow and temperature characteristics and the radiation heat exchange were investigated in the catalytic combustion furnace. Meanwhile, performance tests of frost resistance and water absorption were carried out and applications of glazed tiles were also explored for the architectural decoration of buildings.

\section{EXPERIMENTAL SET-UP}

The flow and temperature characteristics of the combustion of fuel-lean mixtures of natural gas and air were investigated in steady-state conditions in a catalytic honeycomb monolith burner furnace.

The system diagram of catalytic combustion furnace was shown in Fig. 1. The furnace body had the shape of a cuboid, whose edges were $500 \mathrm{~mm}$ long, $500 \mathrm{~mm}$ wide and $660 \mathrm{~mm}$ high. It was connected to a practical burner in Pt and Pd metal based honeycomb monolith. The support for all the monoliths tested here was cordierite and its sintering temperature was $1380^{\circ} \mathrm{C}(1653 \mathrm{~K})$. The two square catalytic honeycomb monoliths were installed in the burner each time. The square honeycomb monoliths were $150 \mathrm{~mm}$ wide and $20 \mathrm{~mm}$ long, with square-shaped cells which sectional area was $1 \mathrm{~mm} \times 1 \mathrm{~mm}$. In order to decrease the temperature of mixtures in chamber connected with the monolith entrance, the $20 \mathrm{~mm}$ long blank monoliths were inserted between the chamber and the catalytic monolith entrance as assembly of monolith.

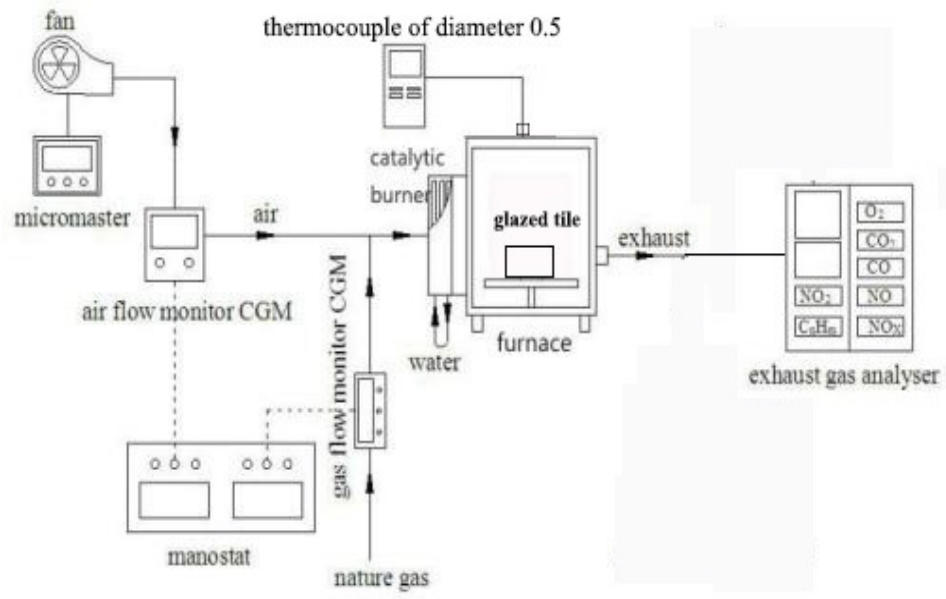

Fig. 1 The system diagram of catalytic combustion furnace

The reactant gas feeds of natural gas and air were regulated via GMS0050BSRN200000 natural gas meter and CMG400A080100000 air meter with $0 \sim 50 \mathrm{~L} / \mathrm{min}$ and $0 \sim 80 \mathrm{~m}^{3} / \mathrm{h}$ of full-scale ranges, respectively. The two meters were provided by electric current. The cooling circulating water was used to cool the burner chamber.

In order to compare performance of the glazed tiles heated by the catalytic combustion furnace with that by electric furnace the glazed tiles were also heated by electric furnace.

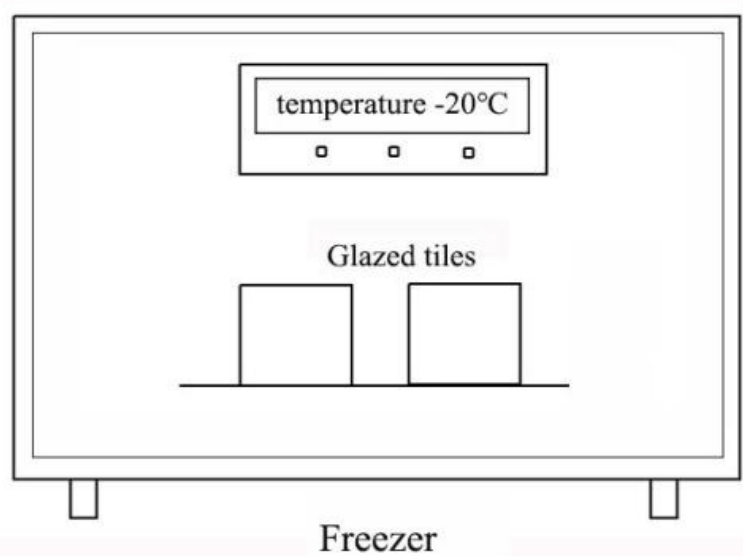

Fig. 2 Schematic of freezer

As shown in Fig.2, the glazed tiles heated by both catalytic combustion furnace and electric furnace were placed inside freezer to test its frost resistance. The temperature was adjusted to $-20{ }^{\circ} \mathrm{C}$.

Two samples of glazed tiles heated by catalytic combustion furnace and were labeled as $X_{1}$ and $X_{2}$. Another two samples of glazed tiles heated by electric furnace were labeled as $\mathrm{Y}_{1}$ and $\mathrm{Y}_{2}$.

The samples had been immersed in water for 24 hours. Then they were placed inside the freezer and taken away after three hours. The samples frozen had been immersed again in water and melted for three hours. This cycle was regarded as one time of frost resistance test every sample. After 15th time performance of frost resistance of the glazed tiles was observed.

\section{EXPERIMENTAL RESULT AND DISCUSSION}

\subsection{Flow and Temperature of Catalytic Combustion Furnace}

The temperature curve of heating glazed tiles inside catalytic combustion furnace of natural gas was shown in Fig. 3. At the time of the ignition at the open end of monolith we recorded it as zero.

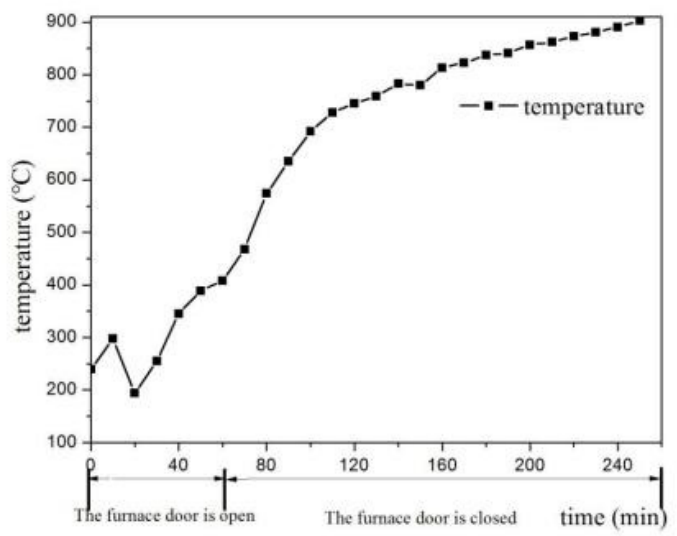


Fig. 3 Temperature curve of heating glazed tiles inside catalytic combustion furnace

The mixture of nature gas and air, rich enough to achieving a blue flame above the monolith was then injected. The blue flame gradually disappeared while the catalyst started glowing red internally. The flow of nature gas was adjusted to the desire lean mixture composition while the catalyst reached steady state. As a catalytic reaction occurs at the interface of a fluid-solid, a large interfacial area is essential in attaining a significant reaction rate for certain catalysts. Due to the adjustment of excess air ratio, the room temperature air volume in lean mixture increased. So that the temperature of furnace had a slight decrease, then the temperature rose slowly again.

After that, temperature inside furnace was increased by adjusting aperture of furnace door and input power of the furnace. As the time increases, the temperature rose steeply before reaching $650^{\circ} \mathrm{C}$. After that, there was a slow rise in the temperature. So that slow rise of temperature is the key to ensure that the bisque has sufficient time to combine with glaze. Therefore, the catalytic combustion furnace is content with condition of temperatures of heating glazed tiles.

The furnace of catalytic honeycomb monolith burner was found possible while preserving near zero emissions as long as surface combustion was taking place.

Radiation heat exchange between the surface of catalytic honeycomb monoliths and the wall surface in an enclosed furnace was regarded as the radiation heat exchange between two gray bodies in an enclosed cavity. It was calculated by Eq. (1):

$$
\phi_{1,2}=\frac{A_{1} \sigma\left(T_{1}^{4}-T_{2}^{4}\right)}{\left(\frac{1}{\varepsilon_{1}}-1\right)+\frac{1}{X_{1,2}}+\frac{A_{1}}{A_{2}}\left(\frac{1}{\varepsilon_{2}}-1\right)}
$$

Where $\mathcal{E}_{1}$ is the emissivity of catalytic honeycomb monoliths surface, which was 0.5 . Its radiation outputs were calculated based on the surface temperatures measured by the infrared pyrometer and using an effective emissivity $\mathcal{E}_{1}$ of 0.5 . The wall surface is surrounded by heat sink. As the material of wall surface was made up of refractory cotton soil, the emissivity $\mathcal{E}_{2}$ was $0.85 . X_{1,2}$ is the shape factors, here was $1, A_{1}$ is the apparent area of the monolith at the open end, which was $A_{1}=0.15 \times 0.3=0.045 \mathrm{~m}^{2}$. The inner casing of furnace still had the shape of a cuboid, whose edges were $370 \mathrm{~mm}$ long, $150 \mathrm{~mm}$ wide and $300 \mathrm{~mm}$ high. $A_{2}$ is the apparent area of the wall surface, which was $A_{2}=0.378 \mathrm{~m}^{2} . T_{1}$ is the average surface temperature of monoliths, which was $1373 \mathrm{~K} . T_{2}$ is the average temperature of the wall surface, which was recorded approximately as $1173 \mathrm{~K}$ by thermocouple K.

In order to improve the quality of glazed tiles further, the temperature rise rate was strictly controlled during the process of heating. Normally the temperature kept at $900^{\circ} \mathrm{C}$ for twenty minutes, the gas flow rate was about $8.0 \mathrm{~L} / \mathrm{min}$ (input power of $4.61 \mathrm{~kW}$ ). The furnace body was supposed to be as an adiabatic system, while partial thermal input of the burner was waste to the surroundings due to the construct of experimental system. The furnace body and burner here are connected as shown in Fig. 1. Thus the radiation heat transfer of the catalytic combustion furnace is calculated to be $2.097 \mathrm{~kW}$. The values of the radiation of the monolith in an enclosed furnace is high.

\subsection{The Properties of Glazed Tiles Heated by Catalytic Combustion Furnace}

The glazed tiles are traditional Architectural Material with the function of decoration and practicability in China. The glazed tile heated by the catalytic combustion furnace was shown in Fig. 4.

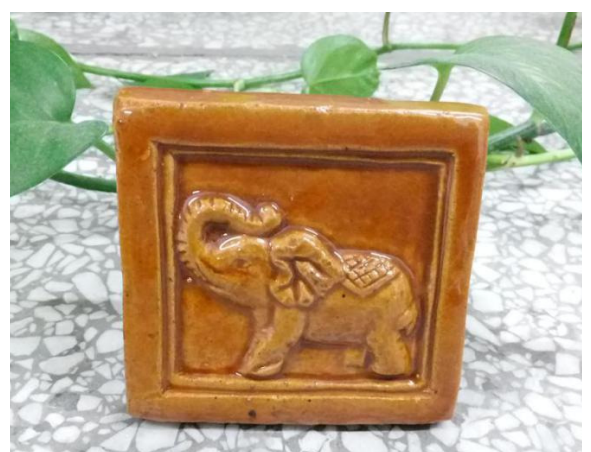

Fig. 4 Glazed tile heated by the catalytic combustion furnace

The glazed tile possessed glossy and transparent glaze. The heating glaze tiles with pure solid texture, rich melodic style and glamorous colors, were obtained. It was found pleasing to both the eye and the mind. It is beautifully shaped. There was the elephant as a pattern which had more auspicious implied meaning and symbol of peace and power.

When applying them to architectural decoration the glazed tiles heated by the catalytic combustion furnace made the traditional Chinese style buildings more magnificent momentum.

In practical aspect, the glazed tiles were meanly used for outdoor. The frost resistance is very important performance in winter. However, water absorption is a key target to affect the frost resistance of glazed tiles.

Higher water absorption of glazed tiles make its frost resistance worse. This also led glaze flaking in a short time. The performance of frost resistance and water absorption of the glazed tiles heated by catalytic combustion furnace and electric furnace were tested at the same time and the data were listed in table 1.

Table 1 The frost resistance and water absorption of the glazed tiles heated by catalytic combustion furnace and electric furnace

\begin{tabular}{cccc}
\hline Sample & $\begin{array}{c}\text { Water } \\
\text { absorption } \\
(\%)\end{array}$ & $\begin{array}{c}\text { Frost } \\
\text { resistance }\end{array}$ & Results \\
\hline $\mathrm{X}_{1}$ & $6 \%$ & Pass 15 times & No damage \\
$\mathrm{X}_{2}$ & $6.3 \%$ & Pass 15 times & No damage \\
$\mathrm{Y}_{1}$ & $8.1 \%$ & Pass 10 times & $\begin{array}{c}\text { The 11th times, } \\
\text { appeared glaze } \\
\text { peeling } \\
\text { The 13th times, } \\
\text { appeared glaze } \\
\text { peeling }\end{array}$ \\
$\mathrm{Y}_{2}$ & $9.2 \%$ & Pass 12 times & $\begin{array}{c}\text { P } \\
\end{array}$
\end{tabular}

National $\quad<12 \quad$ Pass 15 times

standard

The table 1 describes the water absorption and frost resistance of glazed tiles heated by catalytic combustion furnace meeting the Chinese national standard. The glazed tiles heated by electric furnace appeared glaze peeling after the completion of the test as shown in the Fig. 5. It was evidenced that the glazed tiles heated by catalytic combustion furnace proved the high practicality value by the experiment. 


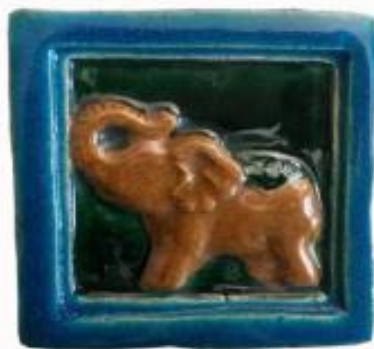

(a) Sample $X_{1}$

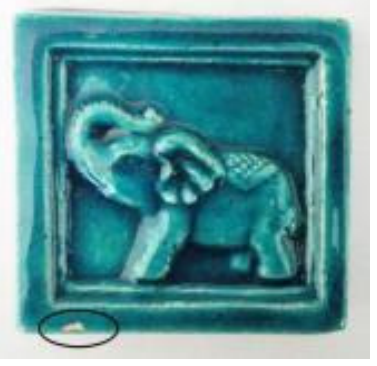

(c) SampleY,

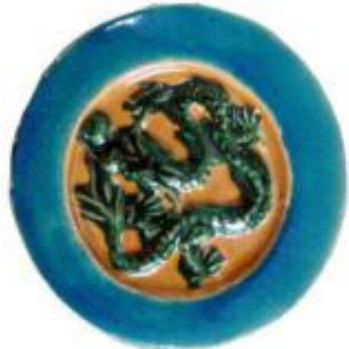

(b) Sample $\mathrm{X}_{2}$

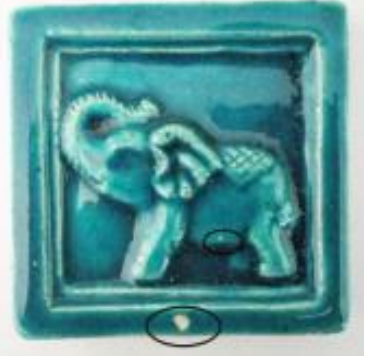

(d) Sample $\mathrm{Y}_{2}$
Fig. 5 Views of glazed tile tested to frost resistance

However, the quality of some new glazed tiles for ancient buildings had passed the relevant test before using. In the process of practical utilization, they could not withstand extremes of temperature and weather without fading or cracking. In view of the facts, the outdoor exposure method was used to investigate the frost resistance. The glazed tiles were placed in the outdoor environment in winter, and the frost resistance of the tiles was observed. This is similar to the actual condition and its result could be a faithful mirror of frost resistance to glazed tiles. The temperature and humidity of outdoor weather were recorded during the period of test.

Table 2 recorded highest temperature and lowest temperature every month. For the four months, the minimum temperature was $-10^{\circ} \mathrm{C}$.

Table 2 The main temperature of four months

\begin{tabular}{lcc}
\hline Month & Highest temperature $\left({ }^{\circ} \mathrm{C}\right)$ & Lowest temperature $\left({ }^{\circ} \mathrm{C}\right)$ \\
\hline December & 3 & -9 \\
January & 0 & -10 \\
February & 4 & -8 \\
March & 8 & -4 \\
\hline
\end{tabular}

As shown in the Fig. 6 and Fig. 7, the temperature and humidity varied from December to March. The average of the lowest and highest temperature per day was taken. For the four months, the monthly temperature fluctuations were truly obvious and the bad weather happened occasionally. However, the glazed tiles heated by the catalytic combustion furnace could mirror the features of the frost resistance when experiencing bad weather. From December to March air humidity fluctuations were also obviously changed in the range of $10 \% \sim 70 \%$. The water which came from air was also harmful to glazed tiles, For four month experiments it is clear that glazed tile heated by catalytic combustion furnace was not damaged and its color was the same as before.

These performance tests of glazed tiles in the experiments could provide a great reference value for the restoration of the Palace Museum.

As traditional architectural materials with a long history glazed tiles are widely used in modern architectural decoration. Traditional House or Modern Building decorated with special colors of glazed tiles showed its unique elegant demeanor in Chinese architectural art.
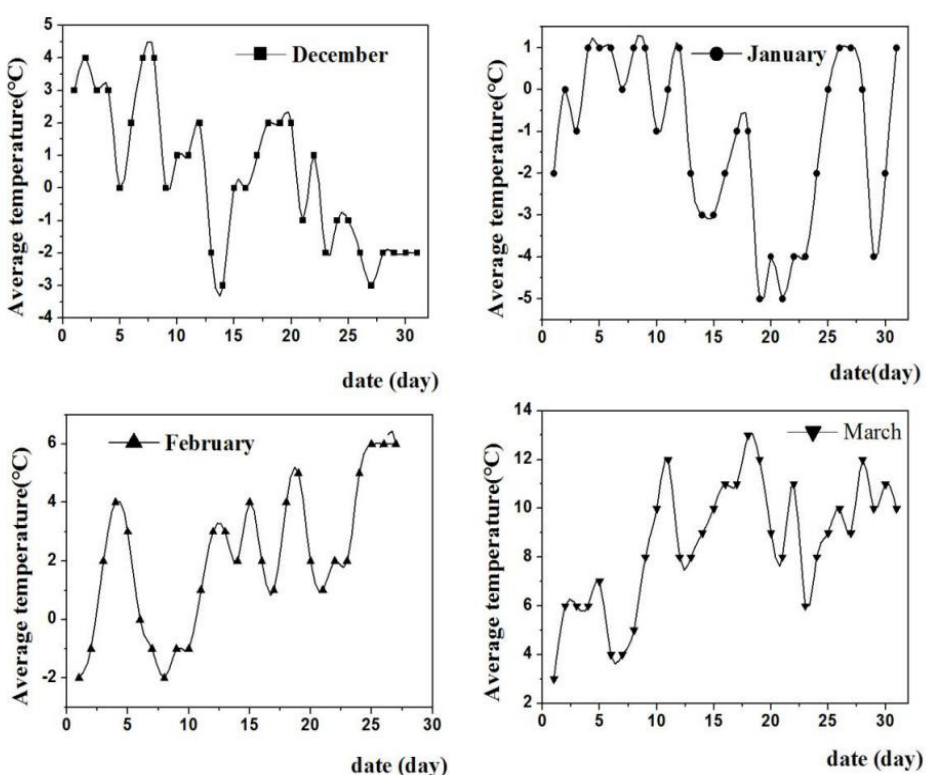

Fig. 6 Curve of outdoor temperature
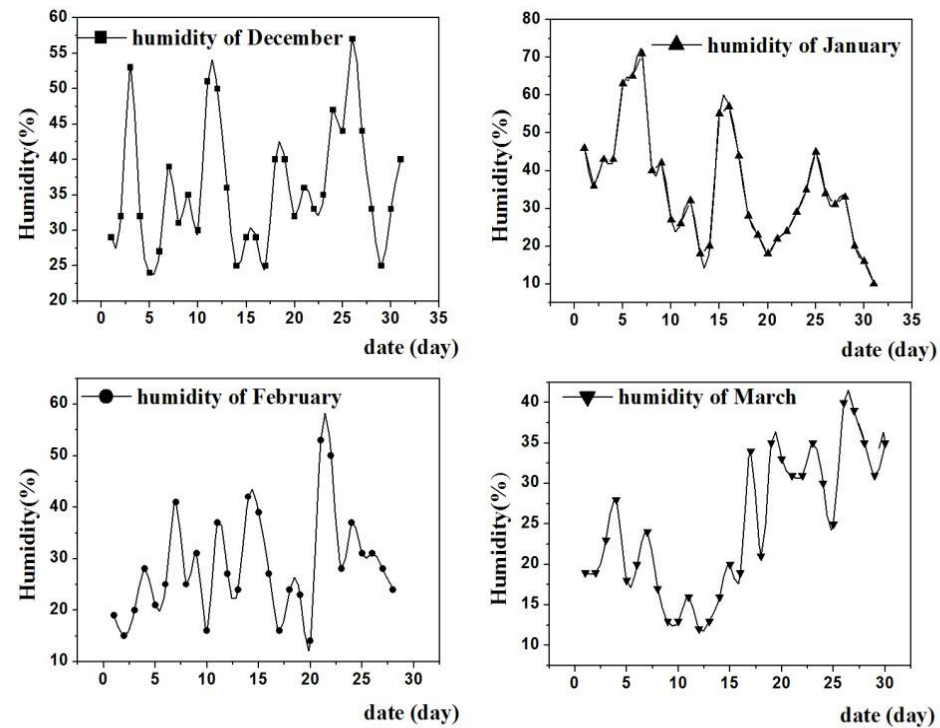

Fig. 7 Curve of outdoor humidity

Although the demand to glazed tiles is increasing. In recent years the relevant industries may have a limited amount of conditions to make glazed tiles.

The over-development industry has become a heavy burden to the environment. However, it pushes people to study on the catalytic burner further and upgrade the equipment. Thus, the catalytic combustion technology has gained popularity and an increasing number of people have worked out the mature technology of catalytic combustion to building an environment-friendly society.

\section{CONCLUSIONS}

During the process of heating the flow and temperature was controlled by adjusting the aperture of furnace door and input power of the furnace. The catalytic combustion furnace is content with condition of flow and temperatures of heating glazed tiles. The high radiation heat transfer in an enclosed furnace played an important role to heating glazed tiles. 
Exhaust gas emissions were measured from catalytic combustion furnace vent consisted of a probe, taking an average exhaust sample. It indicated the advantages of energy-saving and environmental protection. Catalytic combustion played an increasingly important role for lower carbon emissions in industrial applications.

The heating glaze tiles with pure solid texture, rich melodic style and glamorous colors were obtained. The water absorption and frost resistance of the glazed tiles heated by catalytic combustion furnace were tested by a direct evaluation method. The glazed tiles heated by the catalytic combustion furnace could mirror the features of the frost resistance and withstand extremes of temperature and weather without fading or cracking. It is possible to apply the glazed tiles heated by the catalytic combustion furnace to the architectural decoration of buildings.

\section{ACKNOWLEDGMENT}

The project was sponsored by The Fundamental Research Funds for Beijing University of Civil Engineering and Architecture(X18181), Beijing Scholar Program and Beijing Future Urban Design High-Tech Innovation Center.

\section{NOMENCLATURE}

$A_{l} \quad$ apparent area of the monolith at the open end $\left(\mathrm{m}^{2}\right)$

$A_{2} \quad$ apparent area of the wall surface $\left(\mathrm{m}^{2}\right)$

$F \quad$ view factor

$X_{1,2} \quad$ shape factors

$T_{1} \quad$ average surface temperature of monoliths $(\mathrm{K})$

$T_{2} \quad$ average temperature of the wall surface $(\mathrm{K})$

$X_{1} \quad$ glazed tile sample heated by catalytic combustion furnace

$X_{2} \quad$ glazed tile sample heated by catalytic combustion furnace

$Y_{1} \quad$ glazed tile sample heated by electric furnace

$Y_{2} \quad$ glazed tile sample heated by electric furnace

\section{Greek Symbols}

$\Phi_{1,2} \quad$ radiation heat exchange $(\mathrm{kW})$

$\varepsilon_{1} \quad$ emissivity of catalytic honeycomb monoliths surface

$\varepsilon_{2} \quad$ emissivity of wall surface

$\sigma \quad$ the Stephan-Boltzmann constant

\section{REFERENCES}

Cohen A J, Ross A H B, Pandey K D, Ostro B, Kyzyzanowsai M, Kunzli N, Gutschmidt K,Pope A, Romieu I, M.Samet J \&Smith K., "The global burden of disease due to outdoor air pollution". Journal of Toxicology \& Environmental Health Part A, 2005, 68(13-14):1301. https://doi.org/10.1080/15287390590936166

Cheng L, Feng S, Li R, Lv Zh, Li G., "The provenance study of Chinese ancient architectonical colored glaze by INAA." Applied Radiation \&

Isotopes Including Data Instrumentation \& Methods for Use in Agriculture Industry \& Medicine, 2008, 66(12):1873.

https://doi.org/10.1016/j.apradiso.2008.06.039
Dupont, V., Zhang, S.H., and Williams, A., "Catalytic and inhibitory effects of Pt surfaces on the oxidation of $\mathrm{CH} 4 / \mathrm{O} 2 / \mathrm{N} 2$ mixtures", Int. J. Energy Res., 2000, pp.1291-1309.

Gomez-Tena M P, Berto A M, Solsona E B, S Cook,Cercos MG., "Fritless Tile Glazes". Ceramic Industry, 2009.

R.F.Hicks, H.Qi, M.L.Young R.G.Lee, W.J.Han, A.B.Kooh.,"Effect of catalyst structure on the rate of alkane oxidation over platinum". Chemical Engineering Science, 1990, 45(8):2647-2651.

https://doi.org/10.1016/0009-2509(90)80154-7

Jannasch A K, Silversand F, Berger M, Dupuis B, Tena E., "Development of a novel catalytic burner for natural gas combustion for gas stove and cooking plate applications". Catalysis Today, 2006, 117(4):433-437.

https://doi.org/10.1016/j.cattod.2006.06.020

Li J, Zuo S, Qi C., "Preparation and high performance of rare earth modified Co/USY for benzene catalytic combustion", Catalysis Communications, 2017, 91:30-33. https://doi.org/10.1016/j.catcom.2016.12.011

L. D. Pfefferle, W. C. Pfefferle., "Catalysis in Combustion”. Catalysis Reviews, 1987, 29(2-3):219-267.

http://dx.doi.org/10.1016/j.cattod.2006.06.020

Li J, Hu R, Zhang J, Meng W, Du Y, Si Y, Zhang Z., "Influence of preparation methods of $\mathrm{La} 2 \mathrm{CoMnO}_{6} / \mathrm{CeO}_{2}$, on the methane catalytic combustion". Fuel, 2016, 178:148-154.

https://doi.org/10.1016/j.fuel.2016.03.041

Lee J H, Trimm D L., "Catalytic combustion of methane". Fuel Processing Technology, 1995, 42(2 - 3):339-359. https://doi.org/10.1016/0378-3820(94)00091-7

M. Zwinkels, S. Jaras, P.G. Menon, T. Griffin., "Catalytic Materials for High-Temperature Combustion”. Catalysis Reviews, 1993, 35(3):319358.

https://doi.org/10.1080/01614949308013910

Pfefferle, W. C., 1975, "Catalytically-Supported Thermal Combustion," US, US3928961.

Ronney P D., "Analysis of non-adiabatic heat-recirculating combustors". Combustion \& Flame, 2003, 135(4):421-439. https://doi.org/10.1016/j.combustflame.2003.07.003

Wang X Y, Zhu L Q, Zhang S H., "Study on Low-Carbon Catalytic Combustion Furnace of Natural Gas and the Application in Greenhouse". Advanced Materials Research, 2013, 788(4):298-301. https://doi.org/10.4028/www.scientific.net/AMR.1070-1072.1700

Yuan T, Lai Y H, Chang C K., "Numerical studies of heterogeneous reaction in stagnation flows using one-dimensional and twodimensional Cartesian models". Combustion \& Flame, 2008, 154(3):557-568.

http://dx.doi.org/10.1016/j.combustflame.2008.06.005 